This item was submitted to Loughborough's Research Repository by the author.

Items in Figshare are protected by copyright, with all rights reserved, unless otherwise indicated.

\title{
Mechanical and hydrolytic properties of thin polylactic acid films by fused filament fabrication
}

PLEASE CITE THE PUBLISHED VERSION

https://doi.org/10.1016/j.jmbbm.2020.104217

PUBLISHER

Elsevier

VERSION

AM (Accepted Manuscript)

\section{PUBLISHER STATEMENT}

This paper was accepted for publication in the journal Journal of the Mechanical Behavior of Biomedical Materials and the definitive published version is available at https://doi.org/10.1016/j.jmbbm.2020.104217.

\section{LICENCE}

CC BY-NC-ND 4.0

\section{REPOSITORY RECORD}

Ekinci, Alper, Andy Gleadall, Andrew Johnson, Ling Li, and Xiaoxiao Han. 2020. "Mechanical and Hydrolytic Properties of Thin Polylactic Acid Films by Fused Filament Fabrication". Loughborough University. https://hdl.handle.net/2134/13286405.v1. 


\title{
Mechanical and Hydrolytic Properties of Thin Polylactic Acid Films by Fused Filament Fabrication
}

\author{
Alper Ekinci ${ }^{\mathrm{a}}$, Andy Gleadall ${ }^{*}$, Andrew A. Johnson ${ }^{\mathrm{b}}$, Li Ling $^{\mathrm{c}}$, Xiaoxiao Han ${ }^{\mathrm{c} *}$ \\ ${ }^{a}$ Wolfson School of Mechanical, Electrical and Manufacturing Engineering, Loughborough \\ University, Loughborough, LE11 3TU, UK \\ ${ }^{b}$ School of Design \& Creative Arts, Loughborough University, Loughborough, LE11 3TU, UK \\ ${ }^{c}$ State Key Laboratory of Advanced Design and Manufacturing for Vehicle Body, Hunan \\ University, 410082, China
}

\begin{abstract}
Thin polymeric films are widely used as medical applications such as cell culture, stent, drug delivery and mechanical fixation. One of the most commonly used materials is polylactic acid (PLA) - a material, which is non-toxic, biodegradable and biocompatible. In fused filament fabrication (FFF), an additive manufacturing technique, thin films can be manufactured using PLA. FFF is a promising technique for customised biomedical applications due to its relatively low cost and geometrical flexibility where biomedical applications are patient tailored. This study is the first to consider FFF monolayered thin films in terms of mechanical and hydrolytic properties at $37^{\circ} \mathrm{C}$ in vitro degradation. Throughout degradation, the reduction in mechanical properties was examined by analysing molecular weight and thermal properties. Young's modulus, ultimate tensile strength and molecular weight reduced by approximately $60 \%, 86 \%$, and $80 \%$ after 280 days, respectively, while the degree of crystallinity increased by $143 \%$ in comparison to benchmark thin films at day 0 . This study provides practical information in terms of mechanical properties to support medical device designers in a range of potential end-use
\end{abstract}


biomedical applications to achieve safe functional products over the required degradation lifetime.

Keywords: additive manufacturing, fused filament fabrication, polylactic acid, monolayered thin film, hydrolytic degradation, mechanical properties

\section{Introduction}

Of all aliphatic polymers, polylactic acid (PLA) is a relatively cheap thermoplastic, is easy to process, is non-toxic, and produced from renewable resources (Gonzalez Ausejo et al., 2018). In addition, PLA can be metabolised by biological activities, and therefore, assuming that a PLA-based device is appropriately designed and manufactured, there is no need for surgery to remove such an implant from the body (Ginjupalli et al., 2017). PLA possesses a large range of mechanical and physical properties which when combined with its biodegradability and biocompatibility by hydrolytic or enzymatic degradation, can be utilised for the design and manufacture of temporary biomedical devices (Tyler et al., 2016). Hydrolysis is mostly chosen comparing to enzymatic degradation due to insignificant alteration among patients in terms of the degradation rate in the human body (Gunatillake et al., 2003; Maitz, 2015; Nair and Laurencin, 2007). The degradation is water involved, and cleavage of the ester bonds is primarily presented through the backbone of the PLA (Hayashi, 1994). Carboxylic acid end groups cause hydrolysis. Therefore, hydrolytic degradation of the polymer lead to autocatalysis (Siparsky et al., 1998). Due to autocatalysis, immersing a polymer in a $7.4 \mathrm{pH}$ at $37^{\circ} \mathrm{C}$ causes bulk hydrolysis where there is no change in size and shape; however, the structure is weakened. (Laycock et al., 2017). Hydrolytic degradation behaviour of PLA and PLA-based compounds in neutral environments have been widely studied (Fukushima et al., 2011; Mainil-Varlet et al., 1997; Proikakis et al., 2006; Saha and Tsuji, 2006; Vieira et al., 2011; Weir et al., 2004). 
It has been examined that the degradation rate of a polymer is dependent on a number of complex features (Karamanlioglu et al., 2017). Molecular weight is the most significant factor where a high molecular weight increases the degradation time and has shown to significantly impact the degradation rate (Mauduit et al., 1996). Additionally, molecular weight is a principal factor affecting mechanical properties. The degree of crystallinity that consists of both amorphous and crystalline regions is another major feature. Amorphous regions are strongly influenced by hydrolysis compared to crystalline regions during the degradation of PLA as water can diffuse into amorphous domains easily in comparison to crystalline domains (Karamanlioglu et al., 2017). The degree of crystallinity also influences the mechanical properties of PLA, much like molecular weight, where higher-level crystalline specimens demonstrate higher mechanical properties.

There is a range of possible thin biomedical applications of PLA, including, cell carriers, stents, drug delivery, and structural elements to hold tissues or cells together (P. Pawar et al., 2014). Medical applications, being patient-tailored, require precise design, high accuracy and geometrical flexibility. These features are often restricted when traditional manufacturing processes are used. Through the development in Additive Manufacturing (AM) which is used 3-dimensional (3D) digital data, the ability of manufacturing patient based medical applications is materialised (González-Henríquez et al., 2019). One commonly used AM technique is fused filament fabrication (FFF) which is highly suitable for printing PLA. When printing 3D objects with FFF, the raw polymer filament is first melted and then formed through a nozzle to create a layered object in line with user specified process parameters such as infill density, thickness, extrusion temperature, and print bed temperature (Chacón et al., 2017; Dizon et al., 2018; Ekinci et al., 2020; Lanzotti et al., 2015). FFF has high product manufacturing potential and also has the potential to be utilised ahead of some traditional polymer processing methods (Kruth et al., 1998). This technology performs excellent benefits such as high efficiency, 
simplicity, reduced manufacturing and design cycle time, eliminated any tooling, and efficiency on material and as well as cost (Guo and Leu, 2013; Zhai et al., 2014). Since biomedical applications manufactured by FFF are layer by layer, the complex behaviour between printed layers within an FFF object presents a significant challenge (Ngo et al., 2018; Sun et al., 2008), which may inhibit fundamental understanding. Therefore, it is important to initially examine the performance and behaviour of monolayered components. Additionally, thin specimens have direct medical applicability as discussed above. There are no comprehensive studies for mechanical and hydrolytic properties degradation of fused filament fabricated PLA at $37{ }^{\circ} \mathrm{C}$; therefore, the first attempt on the mechanical and hydrolytic properties of monolayered thin films that featured a thickness of $100 \mu \mathrm{m}$ is examined in this study. Additionally, specimens were visually checked, with thermal, molecular weight, mass change, and water uptake were characterised.

\section{Materials and methods}

\subsection{Materials}

$2.85 \mathrm{~mm}$ PLA filament (3DXTECH® branded NatureWorks ${ }^{\circledR}$ polylactide 4043D, Sigma Aldrich, LOT: 85633) was used within this study as a biodegradable polymer. According to the supplier, the PLA filament contains less than $4 \%$ d-isomer. Initial number average molecular weight (Mn) and weight average molecular weight (Mw) were not supplied. Density, glass transition temperature, tensile strength and tensile modulus were given at value of $1.24 \mathrm{~g}$ $\mathrm{cc}^{-1}, 60^{\circ} \mathrm{C}, 56 \mathrm{MPa}$ and $2.865 \mathrm{GPa}$ respectively.

\subsection{Specimen preparation and hydrolytic degradation}

From the raw material through complete degradation, there were four processes; printing, annealing, cutting and degradation, as presented in Figure 1. 


\begin{tabular}{|c|c|c|c|}
\hline Printing & Annealing & Cutting & Degradation \\
\hline $\begin{array}{c}\text { Monolayer thin film } \\
(100 \mathrm{~mm} \text { X } 100 \mathrm{~mm}) \\
100 \mu \mathrm{m} \text { thick }\end{array}$ & $\begin{array}{l}\text { at } 80^{\circ} \mathrm{C} \\
\text { for } \\
2 \text { hours }\end{array}$ & $\begin{array}{l}\text { ISO-527 2A } \\
\text { type } 5 \\
7 \text { Specimens }\end{array}$ & $\begin{array}{l}\text { at } 37^{\circ} \mathrm{C} \\
\text { PBS } \\
\text { pH } 7.4\end{array}$ \\
\hline
\end{tabular}

Figure 1. Specimen preparation and degredation method

A monolayer printed thin sheet of PLA with a length and width of $100 \times 100 \mathrm{~mm}$ was manufactured with a layer thickness of $100 \mu \mathrm{m}$. Key manufacturing process parameters such as line width, printing speed, extrusion temperature and bed temperature were set at $0.36 \mathrm{~mm}$, $80 \mathrm{~mm} \mathrm{~s}^{-1}, 210{ }^{\circ} \mathrm{C}$ and $60^{\circ} \mathrm{C}$ respectively. The raster angle was $0^{\circ}$ to the $\mathrm{x}$-direction using a zigzag pattern until completion. Following, a printed sheet was placed between two aluminium plates and subjected to annealing at $80{ }^{\circ} \mathrm{C}$ for two hours. The monolayered thin films were stamped using ISO-527 2A type 5 to generate seven specimens from each sheet. In total, eight sheets were printed and annealed, and 56 specimens were stamped.

For degradation, test specimens were placed in $28 \mathrm{ml}$ screw-top glass bottles. The specimens were submerged in a phosphate-buffered solution (PBS) acquiring a $\mathrm{pH}$ of 7.4. Finally, the bottles that contained specimens were stored in an incubator (Genlab - INC/50/DIG, Wolflabs, UK) at $37{ }^{\circ} \mathrm{C}$. The temperature was kept constant throughout the degradation investigation. In accordance with ISO 13781:2017, the ratio of PBS in millimetres to the mass of the monolayered thin specimens in grams was maintained to at least 30:1 or higher. The $\mathrm{pH}$ of each specimen bottle was regularly measured every 14 days, with the PBS appropriately changed to ensure a $\mathrm{pH}$ a range of $7.4 \pm 0.2$ was maintained. Each degradation time required at least eight monolayered thin tensile specimens where five were used in mechanical testing and three were used for identifying the water intake and mass change. Following measuring mass change, the dried specimens were used to determine molecular weight and thermal properties. The specimens were tested at the same degradation time with 30, 60, 90, 120, 240 and 280 follow up days. 


\subsection{Characterisation}

2.3.1 Water intake and mass change

The masses of three specimens were weighted using an electronic balance (PIONEER $®$ ANALYTICAL, OHAUS, SW) before storing the specimens in the incubator. After each degradation time, the specimens were removed from the oven and then wiped with a paper towel to drain any excessive aqueous media. The specimens were then directly weighted in order to measure the water intake, with mean water intake established using equation 1.

$$
\mathrm{WI}(\%)=((\mathrm{mu}-\mathrm{m} 0) / \mathrm{m} 0) * 100
$$

where $\mathrm{WI}(\%), \mathrm{mu}$ and $\mathrm{m} 0$ were, percentage of water intake, the mass of undried specimen, and initial mass respectively.

The specimens were stored in a vacuum oven (Jeio Tech OV-11, Medline scientific, UK) at $30^{\circ} \mathrm{C}$ for 48 hours at a vacuum of 51 centimetres $\mathrm{Hg}$ Torr to calculate the mass change using equation 2 at each degradation time point.

$$
\operatorname{MC}(\%)=((\mathrm{md}-\mathrm{m} 0) / \mathrm{m} 0) * 100
$$

Where $\mathrm{MC}(\%)$, md and $\mathrm{m} 0$ were, mass change in percentage, dried mass, and initial mass respectively.

\subsubsection{Thermal properties}

Differential Scanning Calorimetry (DSC) (TQ 200) was used to determine specimen thermal properties such as glass transition ( $\mathrm{Tg}$ ), cold crystallisation $(\mathrm{Tc})$ and melting temperatures

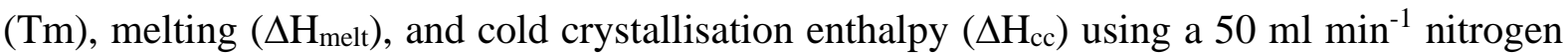
flow rate. Each section for DSC testing weighed approximately $6 \mathrm{mg}$, was extracted from the 
middle of each test specimen, and was tested with $10{ }^{\circ} \mathrm{C} \mathrm{min}{ }^{-1}$ increments from $30{ }^{\circ} \mathrm{C}$ to 200 ${ }^{\circ} \mathrm{C}$. The degree of crystallinity $(\% \chi)$ was calculated using equation 3.

$$
\% \chi=\left(\Delta \mathrm{H}_{\mathrm{melt}}-\Delta \mathrm{H}_{\mathrm{cc}}\right) / \Delta \mathrm{H}_{\mathrm{ref}}
$$

Where $\Delta \mathrm{H}_{\text {ref }}$ was referenced as $93.64 \mathrm{~J} \mathrm{~g}^{-1}$ for $\% 100$ PLLA crystalline.

\subsubsection{Molecular weight}

Number average and weight average molecular weight, and their distribution, Polydispersity index, (PDI) (Mw/Mn) were determined using Waters $^{\circledR}$ Breeze $^{\mathrm{TM}} 1515$ Gel Permeation Chromatography (GPC) system (2414 differential detector) with a chromatographic column of Agilent PLgel $5 \mu \mathrm{m}$ MIXED-C (GB). Thin films cut from the centre of the specimen dissolved in chloroform at a concentration of $2 \mathrm{mg} \mathrm{ml}^{-1}$. Average and standard deviation were obtained using of two measurements. The temperature was kept at $35{ }^{\circ} \mathrm{C}$ with a flow rate of $1 \mathrm{ml} \mathrm{min}{ }^{-1}$ and polystyrene used as a standard material.

The hydrolysis mechanism is regarded to be uncatalysed and autocatalyzed (Lyu et al., 2007). Both uncatalysed and autocatalysed degradation model can be used to calculate the hydrolysis rate. In uncatalysed degradation, the water cleaves the ester bonds, and there should be a linear relationship between time and 1/Mn for each degradation time. The equation 4 is used for uncatalysed degradation (Lyu et al., 2007):

$$
1 / \mathrm{Mn}_{\mathrm{t}}=1 / \mathrm{Mn}_{0}+\mathrm{kt}
$$

Where, $\mathrm{Mn}_{\mathrm{t}}, \mathrm{Mn}_{0}, \mathrm{k}$ and $\mathrm{t}$ are defined as $\mathrm{Mn}$ at time $\mathrm{t}$ and initial, degradation constant rate and time respectively.

PLA which is a condensation polymer is an insoluble polymer in aqueous media, and therefore the hydrolysis of ester bonds requires an aqueous media which is an important constituent to 
form carboxyl and hydroxyl end groups to facilitate its diffusion into the cleaving ester bonds. Cleaving ester bonds can be achieved by catalysation of the carboxyl end groups of oligomers and monomers and results in autocatalytic degradation. An autocatalysed model was created based on carboxylic acid end groups and followed equation 5 (Pitt and Zhong-wei, 1987):

$$
\mathrm{d}[\mathrm{E}] / \mathrm{dt}=-\mathrm{d}[\mathrm{COOH}] / \mathrm{dt}=-\mathrm{k}[\mathrm{COOH}]\left[\mathrm{H}_{2} \mathrm{O}\right][\mathrm{E}]
$$

where, $[\mathrm{COOH}]$ is concentrations of carboxyl end groups, $\left[\mathrm{H}_{2} \mathrm{O}\right]$ is water and $[\mathrm{E}]$ is esters.

The ester bond cleavage rate is proportional to time according to the basic hydrolysis kinetics model. Presuming the water and ester are constant, the final autocatalysed model related to molecular weight can be given as shown in equation 6 :

$$
\mathrm{Mn}_{\mathrm{t}}=\mathrm{Mn}_{0} \mathrm{e}^{\mathrm{kt}}
$$

This equation can be then interpreted to find equation 7 :

$$
\operatorname{lnMn}=-\mathrm{kt}+\ln \mathrm{Mn}_{0}
$$

\subsubsection{Mechanical properties}

Mechanical properties were measured using a universal testing system (Instron 3345 with a $5000 \mathrm{~N}$ load cell) under a speed of $1 \mathrm{~mm} \mathrm{~min}^{-1}$. Following removal from the aqueous media in accordance with ISO 13781:2017 standard, five monolayer tensile specimens were wet during testing. From these five specimens, an average and standard deviation of Young's modulus (E) and ultimate tensile strength (UTS) were determined. 


\section{Results and discussion}

The degraded thin film specimens were visually inspected, and molecular weight and thermal properties determined. Following, the mechanical properties were calculated to understand how the properties decreased through degradation.

\subsection{Visual examination}

Degraded monolayered thin specimens at each degradation time are presented in Figure 2. The non-degraded specimens were opaque, and the colour changed from opaque to white during degradation, as shown in Figure 2.

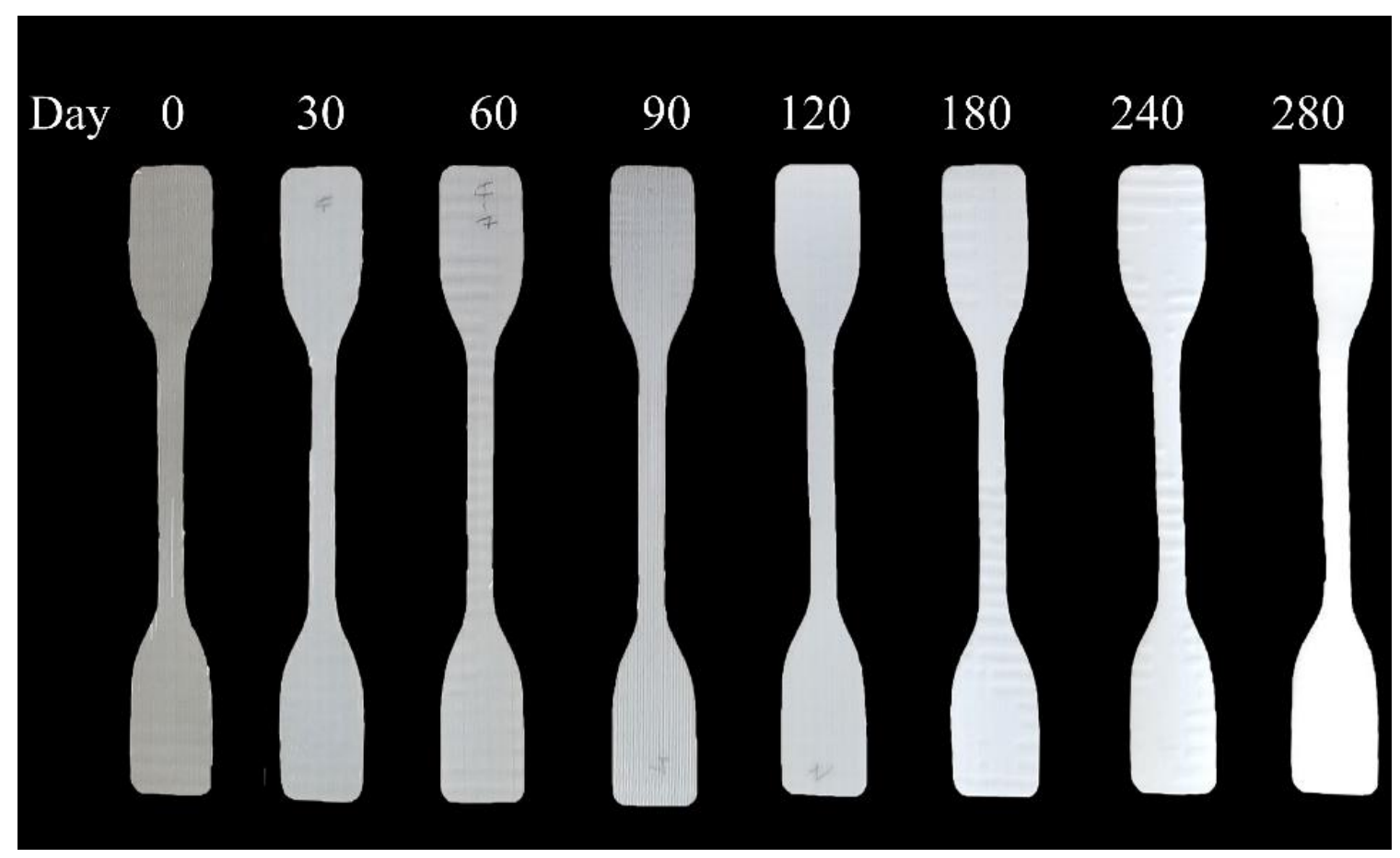

Figure 2. Visual examination of monolayered thin specimens at each degradation time point

The specimens slowly turned to white colour until day 90. It was observed that the complete monolayer specimen shifted to white colour at 120 days. The colour change can be explained due to forming crystal during degradation (Pantani and Sorrentino, 2013). However, the size and shape did not change at each degradation time point. This outcome can give an insight to understand the degradation mechanism of bulk degradation (Tsuji, 2010). 


\subsection{Molecular weight}

Molecular weight is known to be the most significant property that affects degradation, as well as properties such as glass transition temperature, Young's modulus, and UTS. Molecular weight decreased over time during degradation, where at day $0, \mathrm{Mn}$ and $\mathrm{Mw}$ were recorded at $53.95 \mathrm{kDa}$ and $137.80 \mathrm{kDa}$ respectively. Following, obtained values of $\mathrm{Mn}$ and $\mathrm{Mw}$ at each degradation time point are shown in Figure 3.

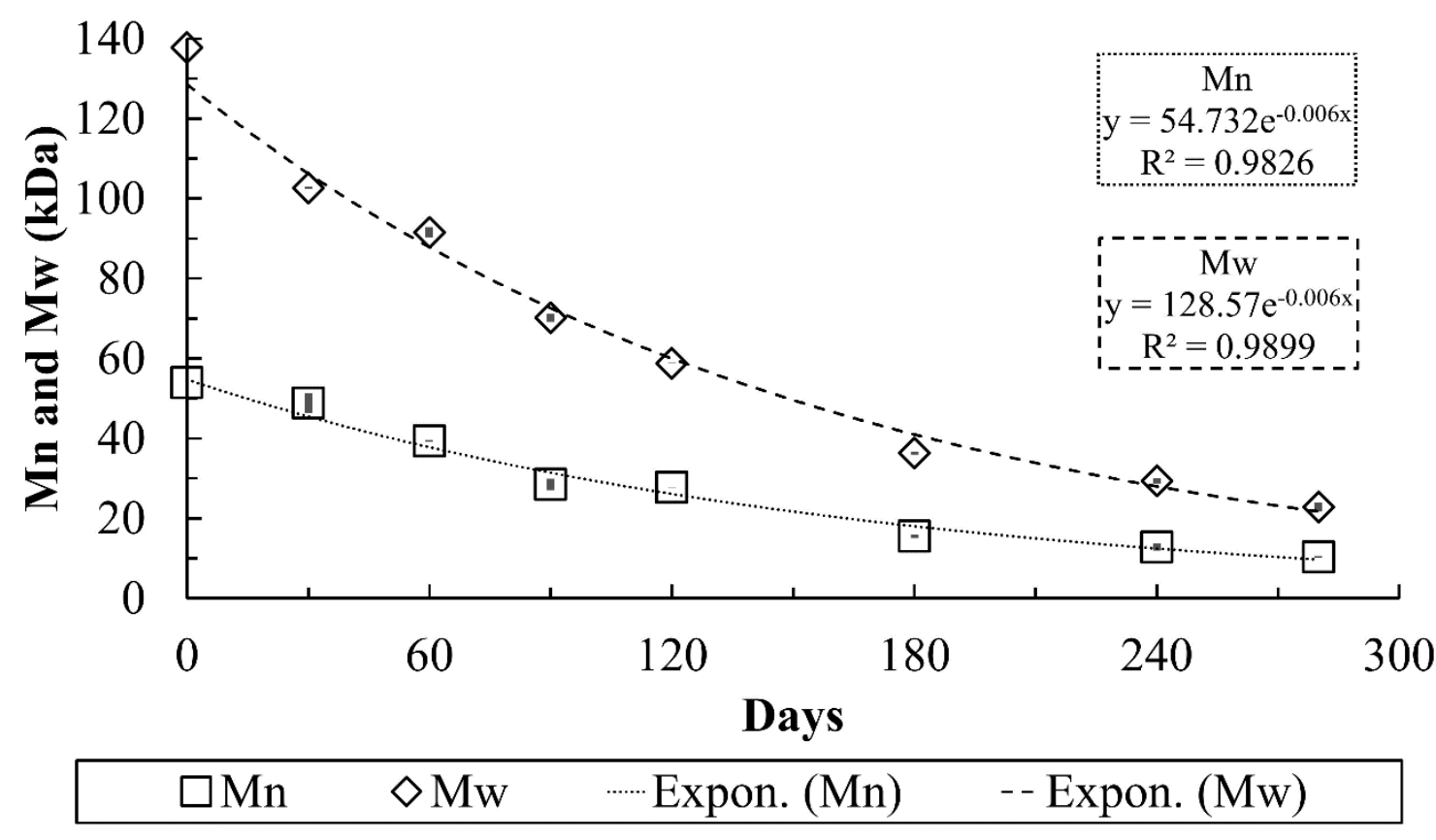

Figure 3. Changes in Mn and Mw of monolayered thin specimen through degradation (gray line inside the markers demonstrates the error bars)

After 30 days, the $\mathrm{Mn}$ and $\mathrm{Mw}$ of the monolayer specimens decreased by $10 \%$ and $25 \%$ respectively. At 120 days the $\mathrm{Mn}$ of specimens were half that originally recorded at day zero, while Mw was halved by day 90. After 280 days, the reduction for Mn and Mw was around $81 \%$ and $83 \%$ respectively, with recorded values of $10.33 \mathrm{kDa}$ and $22.84 \mathrm{kDa}$. Therefore, the PDI demonstrated no obvious pattern and ranged between 2.11 and 2.46. In Figure 3, the Mn and $\mathrm{Mw}$ decreased exponentially with time with a high $\mathrm{R}^{2}$ correlation with the values of 0.97 and 0.99 respectively. 
Analysing the molecular weight data demonstrated in Figure $4 \mathrm{a}$ and Figure $4 \mathrm{~b}$ with equation 4 and equation 7, the degradation rate constant was ascertained using linear regression. Considering the linear equations demonstrated in Figure $4 \mathrm{a}$ and Figure $4 \mathrm{~b}$, the degradation rate constant and correlation coefficient were calculated as presented in Table 1 for monolayered thin specimens for uncatalysed and autocatalysed models. The degradation rate constant was found at a value 0.00029 day $^{-1}$ with high correlation coefficient at 0.97 for uncatalysed model and 0.00617 day $^{-1}$ with high correlation coefficient at 0.98 for the autocatalysed model.
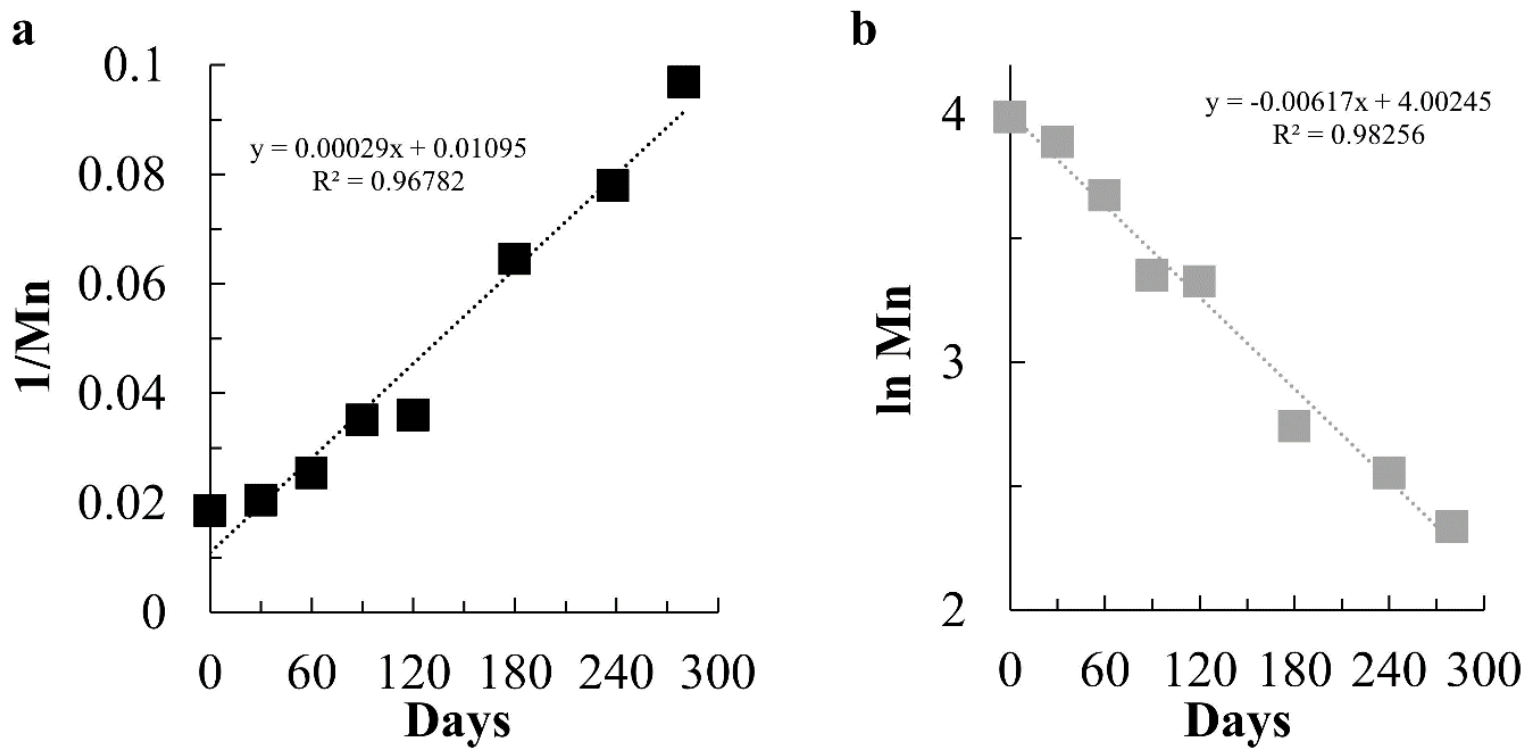

Figure 4. Degradation models a) uncatalysed degradation model (1/Mn vs degradation time) b) autocatalysed degradation model (ln Mn vs degradation time)

\begin{tabular}{c|cc|cc}
\hline Model & \multicolumn{2}{|c|}{ Uncatalysed } & \multicolumn{2}{c}{ Autocatalysed } \\
\hline Temperature & $\mathrm{k}\left(\mathrm{day}^{-1}\right)$ & $\mathrm{R}^{2}$ & $\mathrm{k}\left(\mathrm{day}^{-1}\right)$ & $\mathrm{R}^{2}$ \\
\hline $\mathbf{3 7}^{\circ} \mathbf{C}$ & 0.00029 & 0.9678 & 0.00617 & 0.9826 \\
\hline
\end{tabular}

Table 1. Degradation rate and linear coefficent of monolayer specimen at $37{ }^{\circ} \mathrm{C}$ degradation for uncatalysed and autocatalysed model 
Both the uncatalysed and autocatalysed model showed almost a similar behaviour with a high linear correlation. The uncatalysed hydrolysis theory is validated with the experiments done by Schliecker et al. due to finding no acceleration on degradation with adding oligomers (Schliecker et al., 2003). The autocatalytic hydrolysis theory is supported by other experimental studies (Schliecker et al., 2003; Siparsky et al., 1998; Tsuji, 2002). The autocatalytic model has been widely used on publications because this model is well-matched with the experimental data in aqueous media (Lyu et al., 2007; Schliecker et al., 2003; Tsuji, 2002). Additionally, not taking into account the possibility of autocatalysis accelerated the rate of degradation of the polymer is a disadvantage of uncatalysed approach (Weir et al., 2004).

Utilising GPC enabled the collection of key molecular weight information, therefore obtaining more data about the complex nature of biodegradable polymer degradation, and also providing information about the molecular weight distribution of samples by narrowing the entire GPC chromatogram. GPC chromatograms of the monolayer degraded specimens are presented in Figure 5 at 0,60, 120, and 240 days.

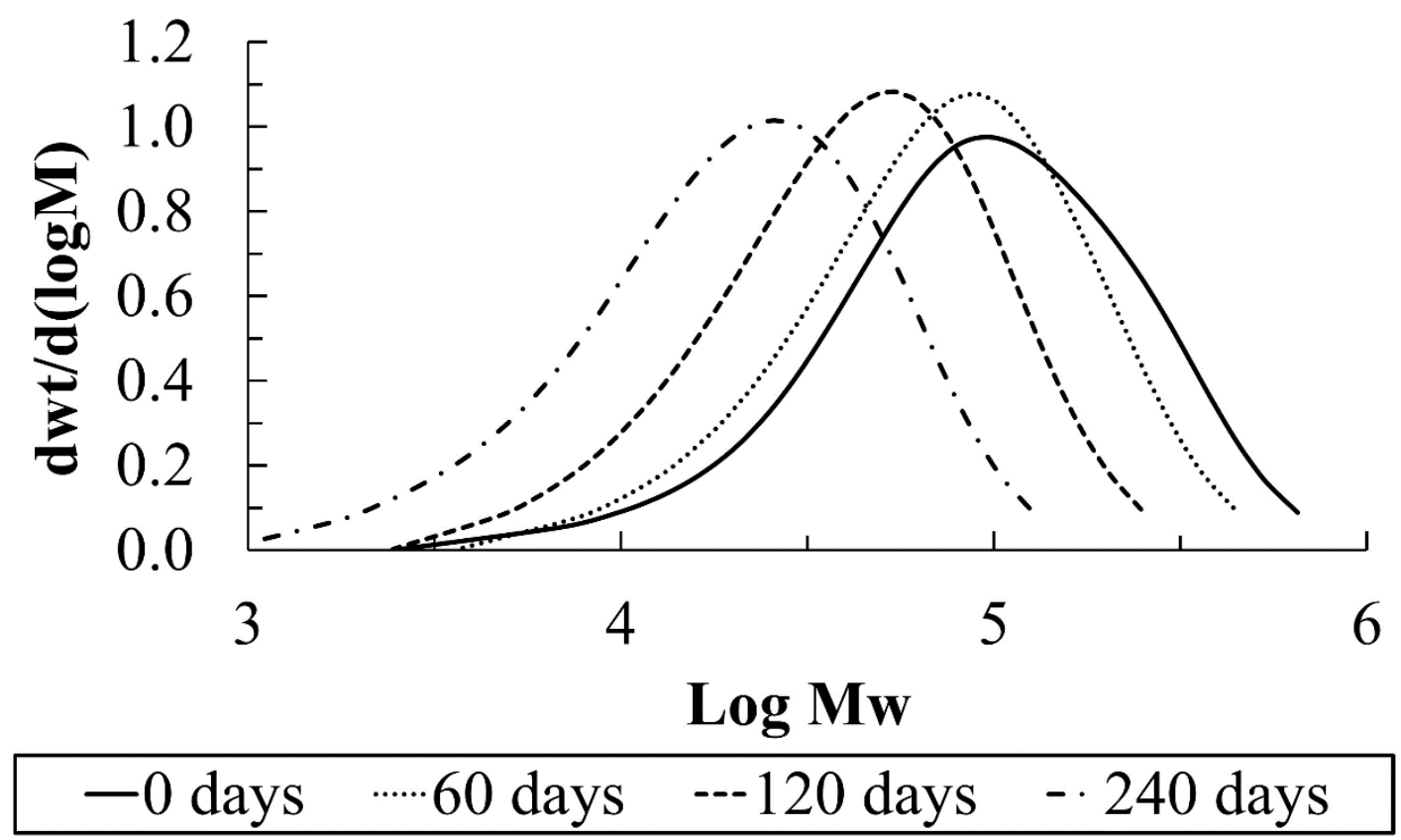

Figure 5. GPC chromatogram of degraded specimen at 0, 60, 120 and 240 days 
With hydrolytic degradation, GPC chromatograms shifted to low molecular weight with similar monomodal distribution.

\subsection{Water Intake and mass change}

The water intake is an amount of absorbed water due to ingress of the aqueous media into the test specimens, and mass loss resulted from oligomers and monomers solved in the aqueous media. In monolayered thin specimens, mass loss and gain were observed therefore, the mass change was calculated. The water intake and mass change of monolayer degraded specimen is presented in Table 2.

\begin{tabular}{|c|c|c|c|c|c|c|c|}
\hline Days & $\mathbf{3 0}$ & $\mathbf{6 0}$ & $\mathbf{9 0}$ & $\mathbf{1 2 0}$ & $\mathbf{1 8 0}$ & $\mathbf{2 4 0}$ & $\mathbf{2 8 0}$ \\
\hline Water Intake (\%) & 0.22 & 0.30 & 0.59 & 0.85 & 2.99 & 3.93 & 18.19 \\
\hline Mass Change (\%) & -0.35 & -0.25 & -0.18 & -0.09 & 0.09 & 0.17 & 0.23 \\
\hline
\end{tabular}

Table 2. Water intake and mass change in percentage for each degradation time period

There was a slight increase in terms of water intake in specimens between 0 to 120 days degradation, ranging from $0.2 \%$ to $0.85 \%$. At 240 days, the water intake increased to approximately 4\%; however, the most notable result from Table 2 is that the water intake increased to $18 \%$ at 280 days. This extreme growth could be ascribed to extensive pores and cracks (Lehtonen et al., 2013). Additionally, water intake can have an effect on the degradation rate where low water intake slows the degradation and can be dependent on molecular weight. The water intake steadily increased until it reached the critical Mn and then it increased substantially. Generally, mass loss of a polymer-based specimen begins when the specimen is immersed in the water and continues until a critical point. However, both mass loss and mass gain has been observed in this study. It can be seen in Table 2 that; the mass loss was $0.35 \%$ at day 30 while the mass gain was $0.23 \%$ at day 280 . The mass gain could be due to aqueous 
media being trapped in the specimens in spite of drying (Ndazi and Karlsson, 2011). This could be interpreted that there was no evidence of mass loss while molecular weight decreased (Shi et al., 2018). Therefore, it can be stated that the monolayer thin specimens demonstrated bulk degradation.

\subsection{Thermal properties}

Table 3 presents thermal properties, including glass transition temperature, melting temperature, and degree of crystallinity of monolayer test specimen at each degradation time point.

\begin{tabular}{|c|c|c|c|c|c|c|c|c|}
\hline Days & $\mathbf{0}$ & $\mathbf{3 0}$ & $\mathbf{6 0}$ & $\mathbf{9 0}$ & $\mathbf{1 2 0}$ & $\mathbf{1 8 0}$ & $\mathbf{2 4 0}$ & $\mathbf{2 8 0}$ \\
\hline $\mathbf{T}_{\mathbf{g}}\left({ }^{\mathbf{0}} \mathbf{C}\right)$ & 60.52 & 61.06 & 63.45 & 62.62 & 59.84 & 55.84 & 54.33 & 49.80 \\
\hline $\mathbf{T}_{\mathbf{m}}\left({ }^{\mathbf{}} \mathbf{C}\right)$ & 150.60 & 150.36 & 150.91 & 150.89 & 153.63 & 152.93 & 152.05 & 149.68 \\
\hline \% G & 20.15 & 23.64 & 25.29 & 27.32 & 32.00 & 36.75 & 42.63 & 48.97 \\
\hline
\end{tabular}

Table 3. Glass transition temperature, melting temperature and degree of crystallinity at each degradation time point

Thermal properties such as glass transition and melting temperatures and the degree of crystallinity are other important factors that affect degradation. As demonstrated in Table 3 , the change in melting temperatures was not significant during degradation. The melting temperature remained similar until 90 days and slightly increased until 240 days and then decreased with increasing degradation time point. Following, the diffusion of aqueous media, at a molecular grade, improves the free volume resulted in increased chain mobility. Therefore, the increase could be related to the development of perfect crystals, while the reduction at 280 days could be associated with surface erosion of the crystalline region (Pantani and Sorrentino, 
2013). However, this is not yet clear, and understanding the decrease in melting temperature requires further investigation.

The glass transition temperature, as presented in Table 3, ranged from $63.45^{\circ} \mathrm{C}$ to $49.80{ }^{\circ} \mathrm{C}$ during degradation. The glass transition temperature remained almost plateau with a slight increase until 60 days. However, the glass transition temperature started to decrease until day 280. It is formulated that glass transition temperature is related to molecular weight and aligns with the Flory-Fox equation as expressed by equation 8 (Fox and Flory, 1954, 1950).

$$
\operatorname{Tg}=\operatorname{Tg}_{\infty}-(\mathrm{K} / \mathrm{Mn})
$$

Where $\mathrm{Tg}_{\infty}$ is the glass transition temperature at infinite molecular weight, and $\mathrm{K}$ is the constant of the free volume end groups. The relationship between glass transition temperature and molecular weight of the degraded specimens is illustrated in Figure 6a.
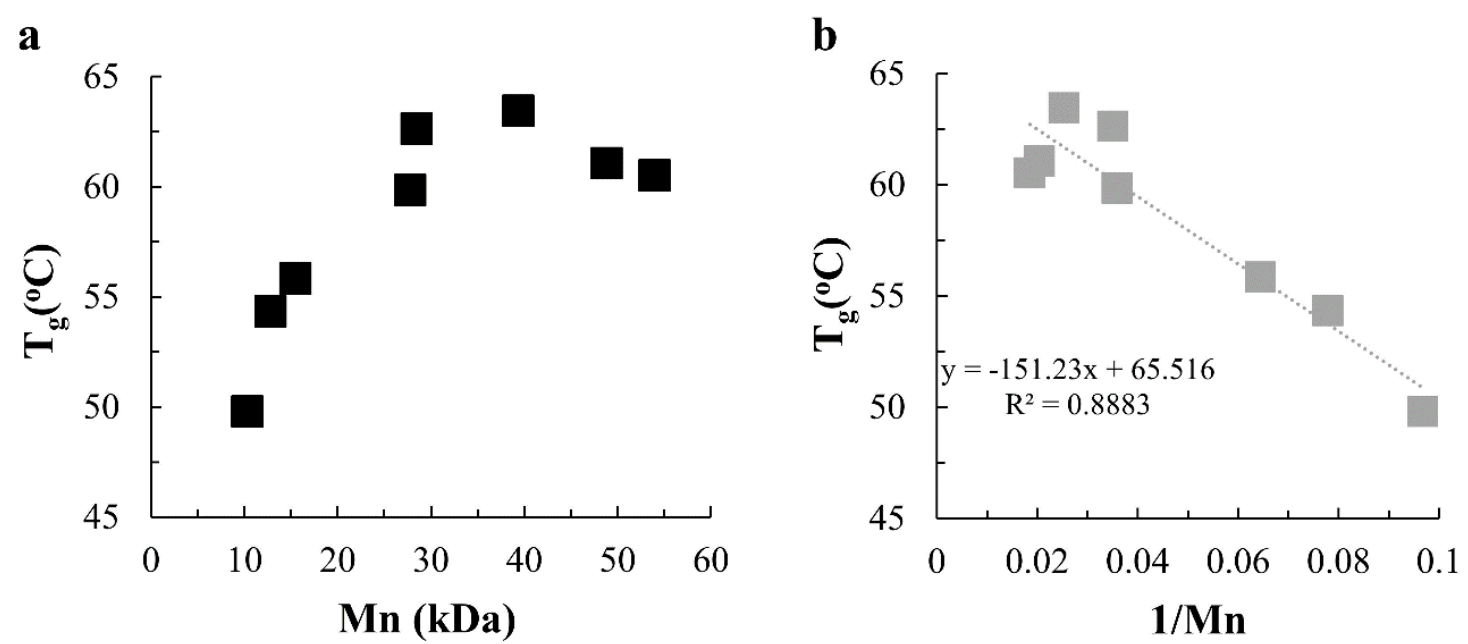

Figure 6. a) Changes in glass transition temperature over molecular weight, b) relationship between glass transition temperature over 1/Mn according to Flory-Fox equation

The glass transition temperature increases with an increased molecular weight until a critical point was reached and then remained constant. By using equation 8 , the $\operatorname{Tg}_{\infty}$ and $\mathrm{K}$ were found and shown in Figure $6 \mathrm{~b}$. The linear coefficient determination, $\mathrm{R}^{2}$, was recorded at 0.89 . The 
glass transition temperature at infinity molecular weight was found to be $65.5^{\circ} \mathrm{C}$ and constant $\mathrm{K}$ calculated at $151{ }^{\circ} \mathrm{C} \mathrm{kDa}^{-1}$ for degraded monolayered thin specimens respectively.

The degree of crystallinity showed an increase during degradation, as presented in Figure 7. Thin specimens increased exponentially with a high $\mathrm{R}^{2}$ at 0.99 . At 280 days, the degree of crystallinity increased by approximately $143 \%$ from $20.15 \%$ to $48.97 \%$.

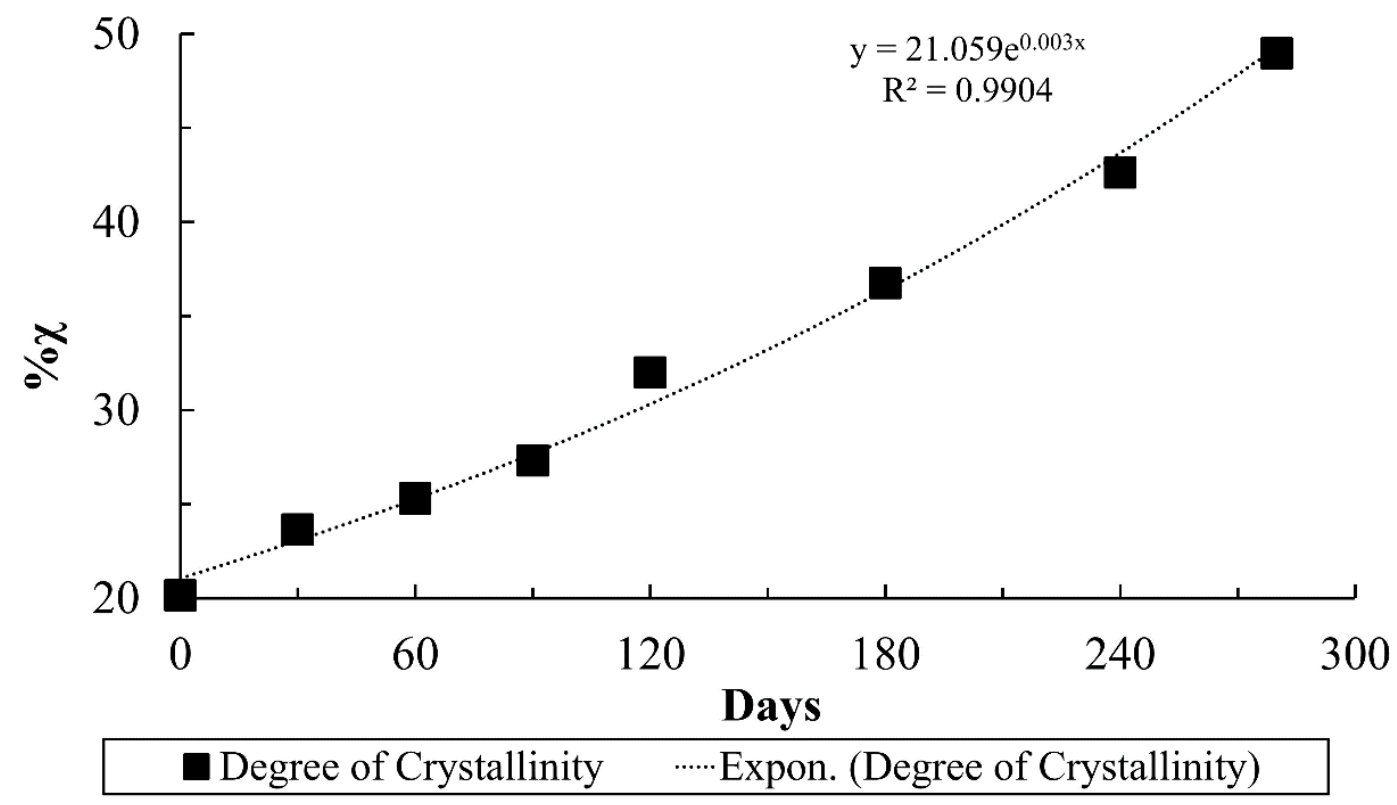

Figure 7. Increase in glass transition temperature through degradation

The chain cleavage during the degradation progress, especially in the amorphous region results in a higher degree of crystallinity. This increase is associated with crystallisation during degradation due to higher chain mobility as a result of the existence of water and a decreased molecular weight (Tsuji and Muramatsu, 2001). Therefore, a relationship between a normalised degree of crystallinity and normalised molecular weight as a function of time is demonstrated in Figure 8. 


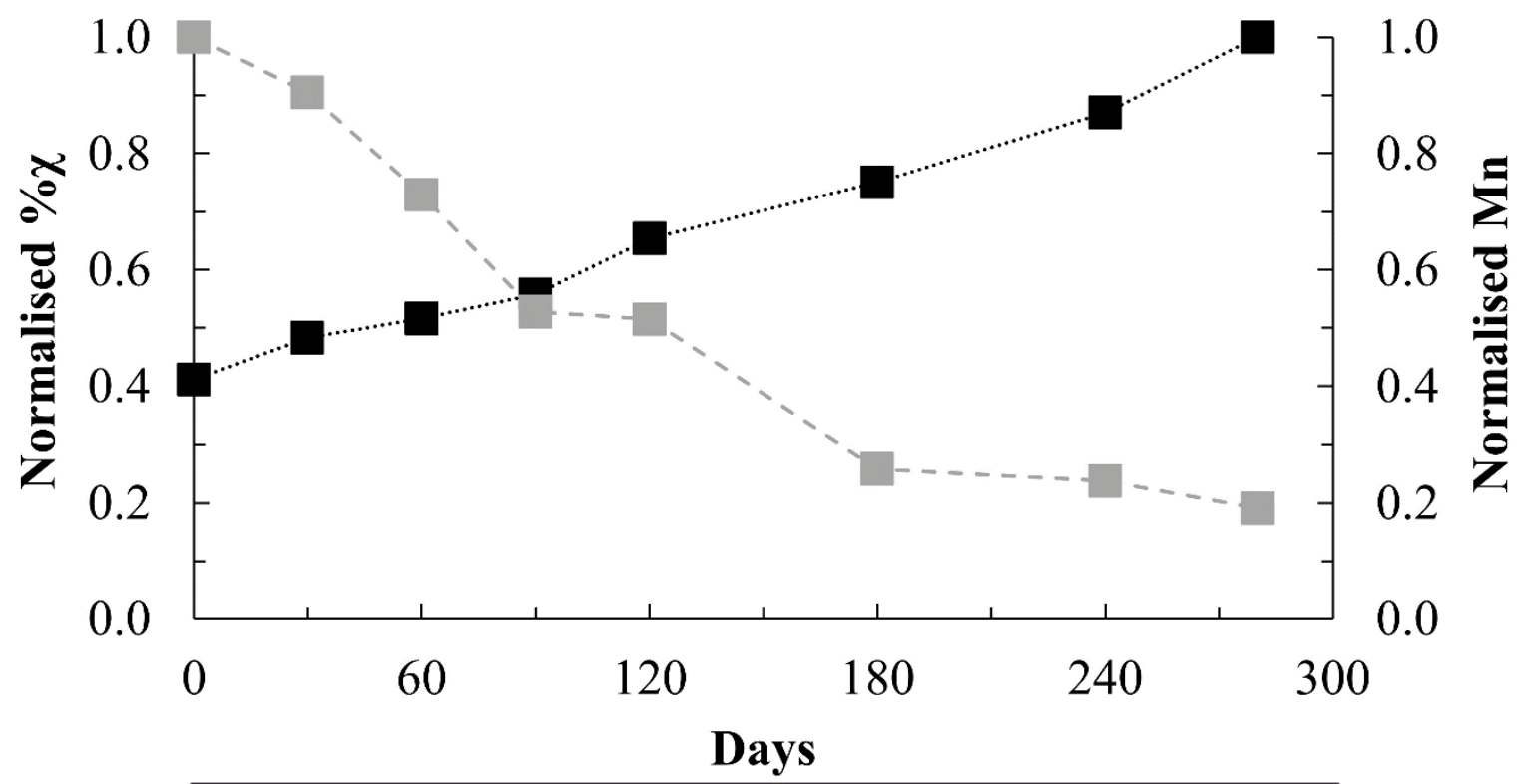

- Normalised $\% \chi \quad$ Normalised Mn

Figure 8. Correlation between normalised degree of crystallinity and molecular weight over normalised time

\subsection{Mechanical properties}

The mechanical properties including Young's modulus and UTS at each degradation time period were calculated from five stress-strain curve, as presented in Figure 9.

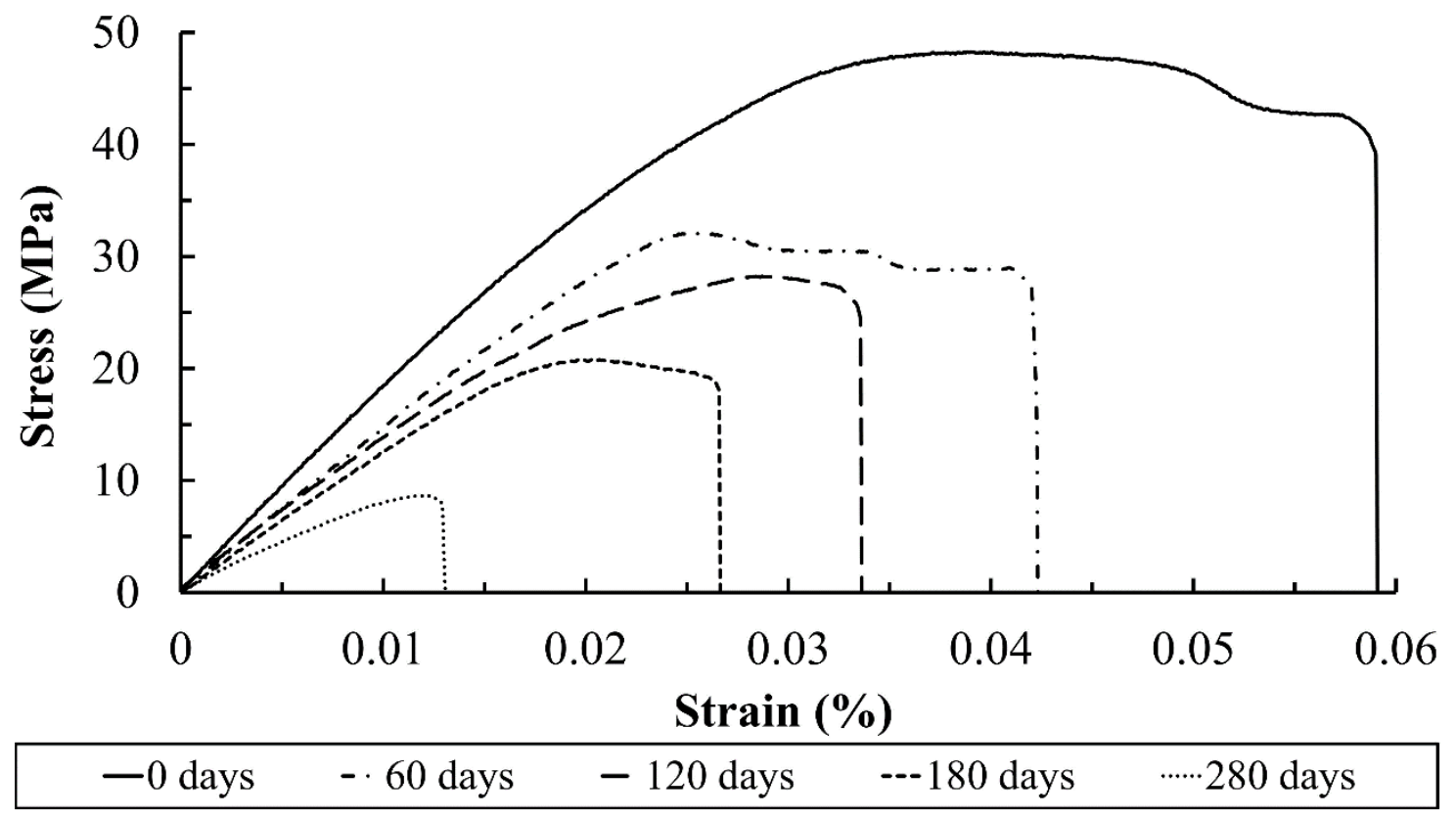

Figure 9. Typical stress-strain behaviour of specimen at 0,60, 120, 180 and 280 days 
Overall, the stress-strain curve for each tested time period shifted from ductile to brittle behaviour with an increasing degradation time. Figure 10 presents a linear reduction in Young's modulus, with a high confidence internal for $\mathrm{R}^{2}$ above $95 \%$, with increasing degradation time.

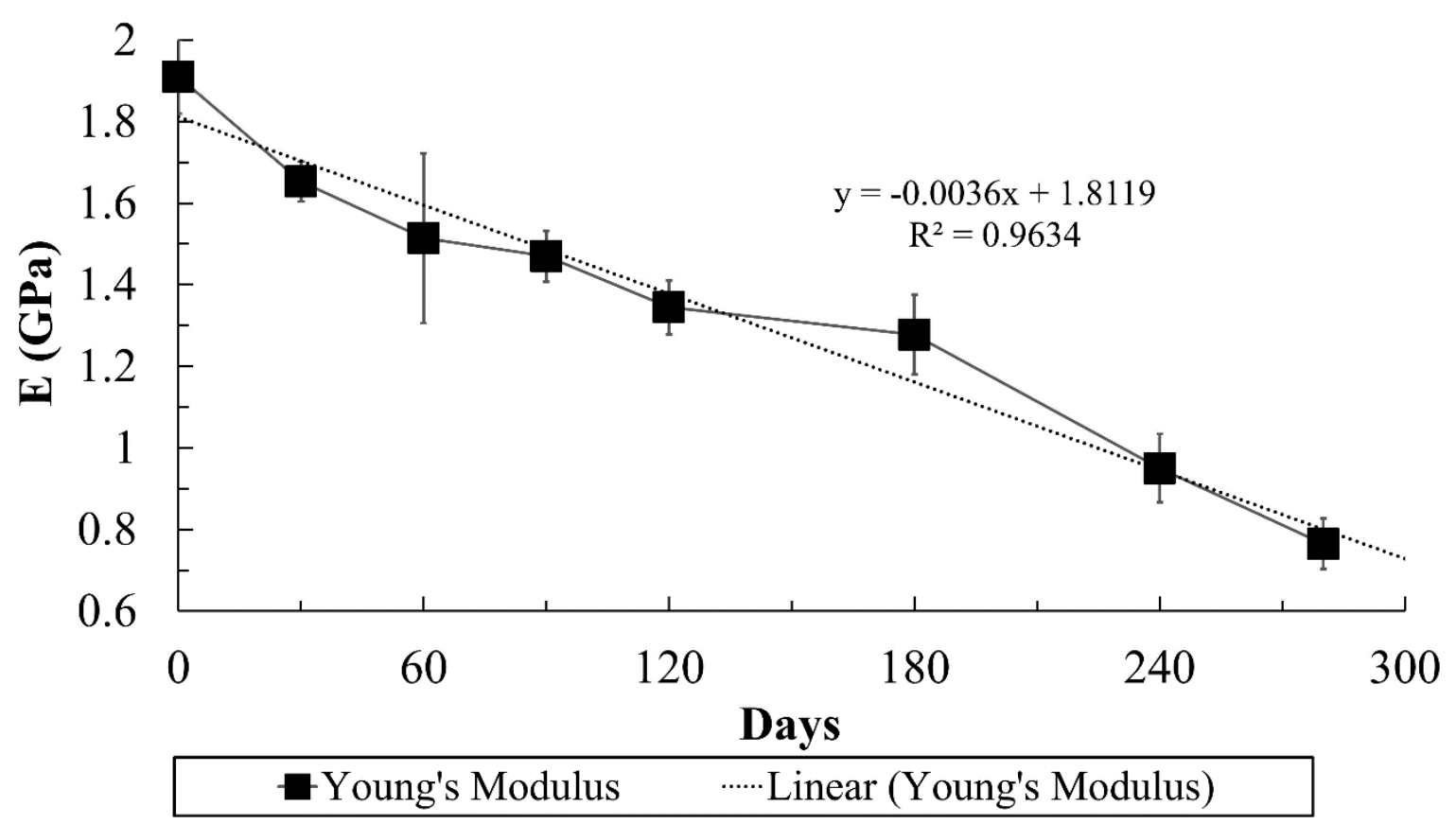

Figure 10. The reduction in Young's modulus over degradation time

The mean Young's modulus was recorded at $1.91 \pm 0.09 \mathrm{GPa}$ at day 0 . At the start of the degradation process, for example, at 30 days and 60 days, the Young's modulus of specimens decreased sharply - decreasing by $13 \%$ at 30 days and by $21 \%$ at 60 days in comparison to benchmarked specimens. Between 60 and 180 days, the decrease in Young's modulus was slower. Monolayer degraded specimens demonstrated a reduction in Young's modulus by approximately $50 \%$ at 240 days in comparison to their initial Young's modulus, while the Young's modulus at 280 days had decreased by approximately $60 \%$.

During degradation, a reduction in Young's modulus was expected. Since biodegradable materials are used for the creation of temporary body implants, understating the reduction rate of Young's modulus was crucial. Young's modulus is also associated with molecular weight. 
The degradation is initiated by chain scission resulting in a decrease in molecular weight and Young's modulus (Ding et al., 2012). Additionally, the chain scission in the lamella of amorphous regions led to a reduction in the Young's modulus (Tsuji et al., 2000). In some previous studies, the Young's modulus initially increased, and there was a delay between a decrease in Young's modulus and decrease in molecular weight. However, this study contradicts those results. In polymers, the lamella is expected to have a robust connection called "tie-chains" (Chu, 1981). Here, the Young's modulus is dependent on the density of the tiechains; therefore, the decrease in Young's modulus would be based on the amount of tie-chain scission where there should be no delay between a decrease in molecular weight and Young's modulus.

Additionally, an entropy-based study for amorphous polymer modelled by Wang et al. demonstrated the relationship between the molecular weight and Young's modulus (Wang et al., 2010). In spite of modelling for amorphous polymer, this theory can be used for semicrystalline polymers with a low degree of crystallinity. Similar behaviour to that presented in Figure 11 has been observed in previous studies. The slow reduction in both Young's modulus and Mn continued until a critical point, in this study this point being approximately $70 \%$ of the initial molecular weight, then a sharp decrease occurred. 


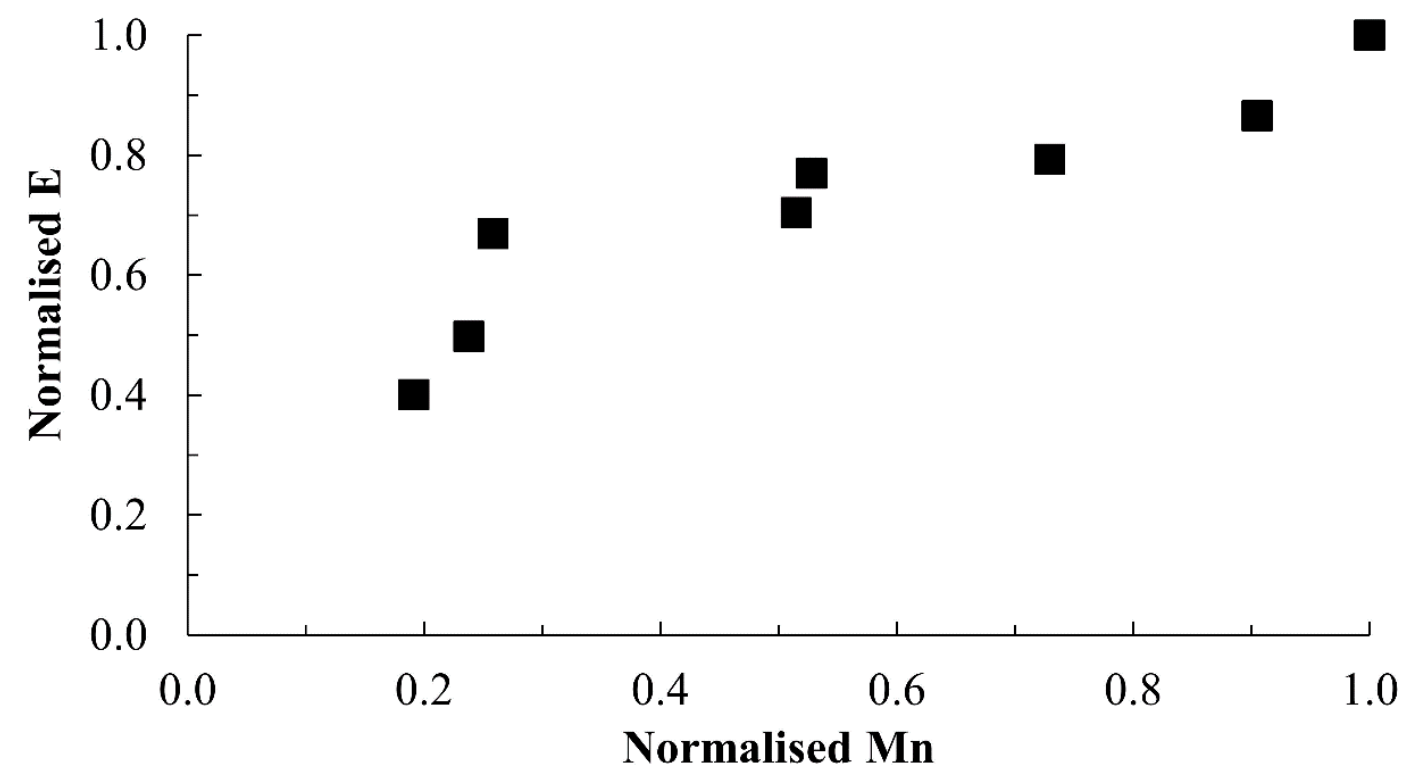

Figure 11: Normalised Young's modulus over normalised molecular weight

As well as Young's modulus and molecular weight, there was also a reduction in UTS through degradation, as shown in Figure 12. The mean UTS at day 0 was 49.28 $\pm 1.64 \mathrm{MPa}$.

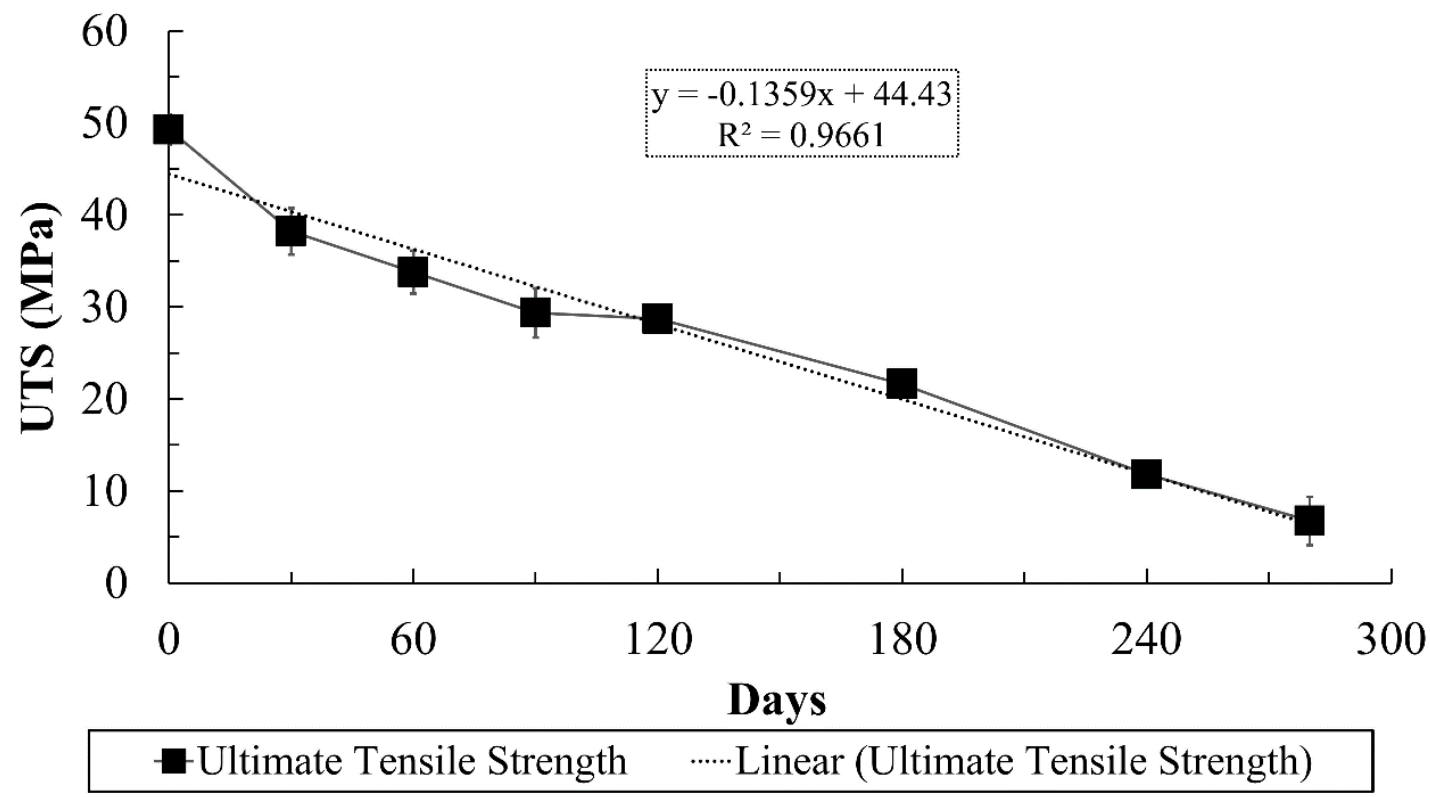

Figure 12: Demonstration of UTS at each degradation time

Monolayered thin specimens lost their UTS by almost $22 \%$ at day 30 in comparison to benchmark specimens at day 0 . At 120 days, the remained UTS was measured at $58 \%$, while 50\% reduction was projected at day 145 using the linear equation demonstrated in Figure 12. 
Following, the UTS decreased by $75 \%$ at 240 days, and finally, the value of UTS decreased to $14 \%$ at 280 days.

There is still remains some uncertainty about the change of tensile strength of specimens following hydrolytic degradation. Tensile strength is influenced by molecular weight and degree of crystallinity. The low molecular weight decreases the strength of the material while increasing the degree of crystallinity enhances stiffness and strength (Zhang et al., 2019). However, the increase in the degree of crystallinity through degradation was moderate. The positive effect of crystallinity on the mechanical tensile strength is less significant than the negative effect of molecular weight on tensile strength (Pan, 2015). Therefore, the witnessed reduction in the mechanical properties of specimens is nearly identical to the decrease in molecular weight, thus the reduction in strength could be directly associated with a decrease in molecular weight. The change in UTS using molecular weight data is presented in Figure 13a.
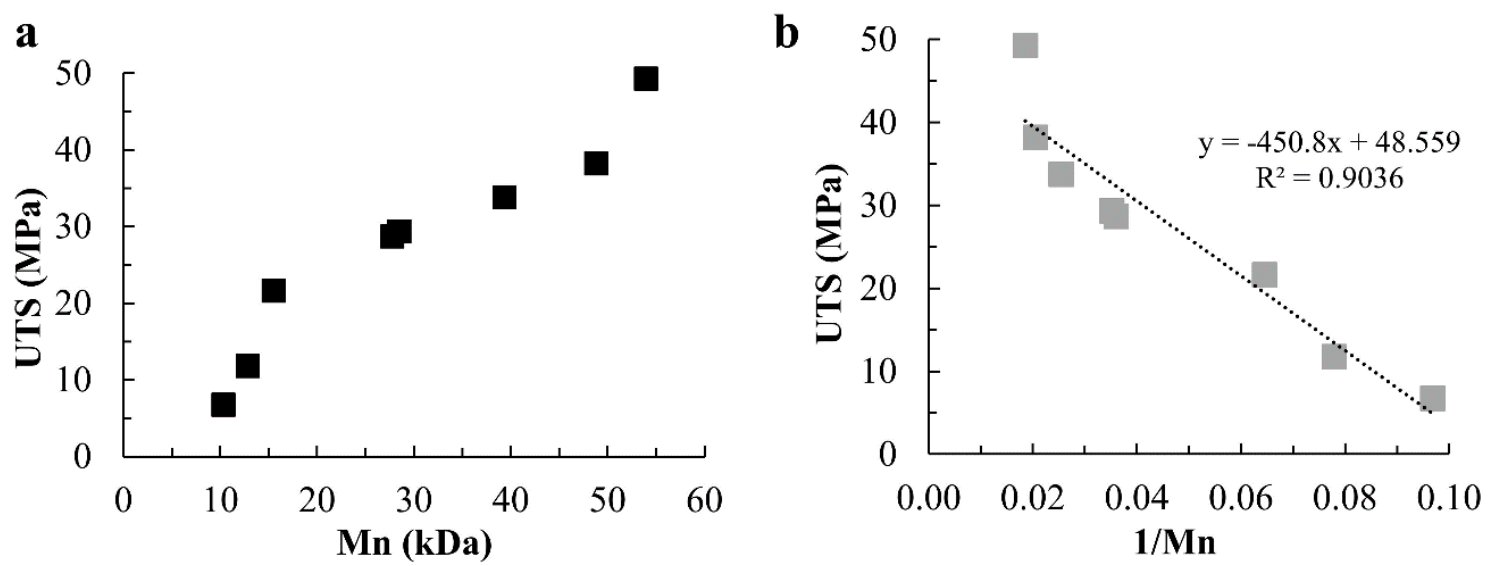

Figure 13: a) Changes in UTS over molecular weight b) linear relationship between UTS and 1/Mn based on Flory's theory

The monolayer specimens followed Flory's theory where the UTS steadily decreased at high molecular weight, with a significant linear decrease occurring with a decrease in Mn. Equation 
9 was used to calculate the tensile strength at infinite molecular weight using Flory's theory (Farrar and Gillson, 2002):

$$
\sigma=\sigma_{\infty}-(\mathrm{A} / \mathrm{Mn}) \text { Equation }
$$

Where; $\sigma, \sigma_{\infty}, \mathrm{A}$ and $\mathrm{Mn}$ are strength, strength at infinite molecular weight, constant and molecular weight respectively. The $\sigma_{\infty}$ and A were calculated using the linear trendline of UTS versus 1/Mn as shown in Figure 13b. The linear coefficient correlation was 0.90 while the UTS at infinite molecular weight was calculated to be $48.56 \mathrm{MPa}$.

\section{Conclusion}

The results and understanding from this study can be potentially applied to enhance the operational performance of bespoke thin biomedical devices for a range of functions. Understanding the degradation effects of the monolayered thin films of a PLA using FFF component is crucial. FFF printed thin films can be manufactured patient based with relatively low cost, reliability and geometrical flexibility. The current study examined the in vitro degradation of monolayered thin films manufactured via FFF at $37^{\circ} \mathrm{C}$ for up to 280 days across seven distinct time points. Molecular weight, mass, thermal, and mechanical properties alongside supporting theories have been presented in order to understand the degradation behaviour of monolayer specimens. The following notable outcomes are obtained from this investigation, including:

- The relationship between the Young's modulus and molecular weight was observed when both Young's modulus and molecular weight were normalised. The Young's modulus steadily decreased by $20 \%$ while the molecular weight decreased by approximately $70 \%$ until day 180 ; whereas, it was followed by a sharp linear 
reduction in Young's modulus, while there was only an additional $10 \%$ reduction in molecular weight.

- $\quad$ The UTS decreased by approximately $22 \%, 50 \%$ and $86 \%$ at day 30,145 and 280 respectively. Monolayered thin films followed Flory's equation in terms of UTS where UTS at infinite molecular weight was recorded at $48.6 \mathrm{MPa}$.

- There was no significant mass change during degradation as monolayer specimens demonstrated autocatalysis bulk degradation with a high linear coefficient at $98 \%$.

\section{Acknowledgement}

This work is supported by the PhD Scholarship for Alper Ekinci from the Ministry of National Education (Republic of Turkey), and also supported by the Huxiang High-level Talent Gathering Project (No. 2019RS1019) from China Hunan Provincial Science and Technology Department.

\section{References}

Chacón, J.M., Caminero, M.A., García-Plaza, E., Núñez, P.J., 2017. Additive manufacturing of PLA structures using fused deposition modelling: Effect of process parameters on mechanical properties and their optimal selection. Materials \& Design 124, 143-157. https://doi.org/10.1016/j.matdes.2017.03.065

Chu, C.C., 1981. Hydrolytic degradation of polyglycolic acid: Tensile strength and crystallinity study. Journal of Applied Polymer Science 26, 1727-1734. https://doi.org/10.1002/app.1981.070260527

Ding, L., Davidchack, R.L., Pan, J., 2012. A molecular dynamics study of Young's modulus change of semi-crystalline polymers during degradation by chain scissions. Journal of the Mechanical Behavior of Biomedical Materials 5, 224-230. 
https://doi.org/10.1016/j.jmbbm.2011.09.002

Dizon, J.R.C., Espera, A.H., Chen, Q., Advincula, R.C., 2018. Mechanical characterization of 3D-printed polymers. Additive Manufacturing $\quad 20, \quad 44-67$. https://doi.org/10.1016/j.addma.2017.12.002

Ekinci, A., Johnson, A.A., Gleadall, A., Engstrøm, D.S., Han, X., 2020. Layer-dependent properties of material extruded biodegradable Polylactic Acid. Journal of the Mechanical Behavior of Biomedical Materials 104. https://doi.org/10.1016/j.jmbbm.2020.103654

Farrar, D.F., Gillson, R.K., 2002. Hydrolytic degradation of polyglyconate B: The relationship between degradation time, strength and molecular weight. Biomaterials 23, 3905-3912. https://doi.org/10.1016/S0142-9612(02)00140-0

Fox, T.G., Flory, P.J., 1954. The glass temperature and related properties of polystyrene. Influence of molecular weight. Journal of Polymer Science 14, 315-319. https://doi.org/10.1002/pol.1954.120147514

Fox, T.G., Flory, P.J., 1950. Second-order transition temperatures and related properties of polystyrene. I. Influence of molecular weight. Journal of Applied Physics 21, 581-591. https://doi.org/10.1063/1.1699711

Fukushima, K., Tabuani, D., Dottori, M., Armentano, I., Kenny, J.M., Camino, G., 2011. Effect of temperature and nanoparticle type on hydrolytic degradation of poly(lactic acid) nanocomposites. Polymer Degradation and Stability 96, 2120-2129. https://doi.org/10.1016/j.polymdegradstab.2011.09.018

Ginjupalli, K., Shavi, G.V., Averineni, R.K., Bhat, M., Udupa, N., Nagaraja Upadhya, P., 2017. Poly( $\alpha$-hydroxy acid) based polymers: A review on material and degradation aspects. 
Polymer Degradation and Stability 144, 520-535. https://doi.org/10.1016/j.polymdegradstab.2017.08.024

González-Henríquez, C.M., Sarabia-Vallejos, M.A., Rodriguez-Hernandez, J., 2019. Polymers for additive manufacturing and 4D-printing: Materials, methodologies, and biomedical applications. Progress in Polymer Science 94, 57-116. https://doi.org/10.1016/j.progpolymsci.2019.03.001

Gonzalez Ausejo, J., Rydz, J., Musioł, M., Sikorska, W., Janeczek, H., Sobota, M., Włodarczyk, J., Szeluga, U., Hercog, A., Kowalczuk, M., 2018. Three-dimensional printing of PLA and PLA/PHA dumbbell-shaped specimens of crisscross and transverse patterns as promising materials in emerging application areas: Prediction study. Polymer Degradation and Stability 100-110. https://doi.org/10.1016/j.polymdegradstab.2018.08.008

Gunatillake, P.A., Adhikari, R., Gadegaard, N., 2003. Biodegradable synthetic polymers for tissue engineering. European Cells and Materials 5, 1-16. https://doi.org/10.22203/eCM.v005a01

Guo, N., Leu, M.C., 2013. Additive manufacturing: Technology, applications and research needs. Frontiers of Mechanical Engineering 8, 215-243. https://doi.org/10.1007/s11465013-0248-8

Hayashi, T., 1994. Biodegradable polymers for biomedical uses. Progress in Polymer Science 19, 663-702. https://doi.org/10.1016/0079-6700(94)90030-2

Karamanlioglu, M., Preziosi, R., Robson, G.D., 2017. Abiotic and biotic environmental degradation of the bioplastic polymer poly(lactic acid): A review. Polymer Degradation and Stability 137, 122-130. https://doi.org/10.1016/j.polymdegradstab.2017.01.009 
Kruth, J.P., Leu, M.C., Nakagawa, T., 1998. Progress in additive manufacturing and rapid prototyping. CIRP Annals - Manufacturing Technology 47, 525-540. https://doi.org/10.1016/S0007-8506(07)63240-5

Lanzotti, A., Grasso, M., Staiano, G., Martorelli, M., 2015. The impact of process parameters on mechanical properties of parts fabricated in PLA with an open-source 3-D printer. Rapid Prototyping Journal 21, 604-617. https://doi.org/10.1108/RPJ-09-2014-0135

Laycock, B., Nikolić, M., Colwell, J.M., Gauthier, E., Halley, P., Bottle, S., George, G., 2017. Lifetime prediction of biodegradable polymers. Progress in Polymer Science 71, 144-189. https://doi.org/10.1016/j.progpolymsci.2017.02.004

Lehtonen, T.J., Tuominen, J.U., Hiekkanen, E., 2013. Resorbable composites with bioresorbable glass fibers for load-bearing applications. in vitro degradation and degradation mechanism. Acta Biomaterialia 9, 4868-4877. https://doi.org/10.1016/j.actbio.2012.08.052

Lyu, Schley, J., Loy, B., Lind, D., Hobot, C., Sparer, R., Untereker, D., 2007. Kinetics and Time-Temperature Equivalence of Polymer Degradation. Biomacromolecules 8, 23012310. https://doi.org/10.1021/bm070313n

Mainil-Varlet, P., Curtis, R., Gogolewski, S., 1997. Effect of in vivo and in vitro degradation on molecular and mechanical properties of various low-molecular-weight polylactides. Journal of Biomedical Materials Research 36, 360-380. https://doi.org/10.1002/(SICI)1097-4636(19970905)36:3<360::AID-JBM11>3.0.CO;2-I

Maitz, M.F., 2015. Applications of synthetic polymers in clinical medicine. Biosurface and Biotribology 1, 161-176. https://doi.org/10.1016/j.bsbt.2015.08.002 
Mauduit, J., Pérouse, E., Vert, M., 1996. Hydrolytic degradation of films prepared from blends of high and low molecular weight poly(DL-lactic acid)s. Journal of Biomedical Materials Research 30, 201-207. https://doi.org/10.1002/(SICI)10974636(199602)30:2<201::AID-JBM10>3.0.CO;2-P

Nair, L.S., Laurencin, C.T., 2007. Biodegradable polymers as biomaterials. Progress in Polymer Science 32, 762-798. https://doi.org/10.1016/j.progpolymsci.2007.05.017

Ndazi, B.S., Karlsson, S., 2011. Characterization of hydrolytic degradation of polylactic acid / rice hulls composites in water at different temperatures 5, 119-131. https://doi.org/10.3144/expresspolymlett.2011.13

Ngo, T.D., Kashani, A., Imbalzano, G., Nguyen, K.T.Q., Hui, D., 2018. Additive manufacturing (3D printing): A review of materials, methods, applications and challenges. Composites Part B: Engineering 143, 172-196. https://doi.org/10.1016/j.compositesb.2018.02.012

P. Pawar, R., U. Tekale, S., U. Shisodia, S., T. Totre, J., J. Domb, A., 2014. Biomedical Applications of Poly(Lactic Acid). Recent Patents on Regenerative Medicine 4, 40-51. https://doi.org/10.2174/2210296504666140402235024

Pan, J., 2015. Modelling Degradation of Bioresorbable Polymeric Medical Devices. Elsevier. https://doi.org/10.1016/C2013-0-16432-X

Pantani, R., Sorrentino, A., 2013. Influence of crystallinity on the biodegradation rate of injection-moulded poly(lactic acid) samples in controlled composting conditions. Polymer Degradation and Stability 98, 1089-1096. https://doi.org/10.1016/j.polymdegradstab.2013.01.005 
Pitt, C.G., Zhong-wei, G., 1987. Modification of the rates of chain cleavage of poly(€caprolactone) and related polyesters in the solid state. Journal of Controlled Release 4, 283-292. https://doi.org/10.1016/0168-3659(87)90020-4

Proikakis, C.S., Mamouzelos, N.J., Tarantili, P.A., Andreopoulos, A.G., 2006. Swelling and hydrolytic degradation of poly(d,l-lactic acid) in aqueous solutions. Polymer Degradation and Stability 91, 614-619. https://doi.org/10.1016/j.polymdegradstab.2005.01.060

Saha, S.K., Tsuji, H., 2006. Effects of molecular weight and small amounts of d-lactide units on hydrolytic degradation of poly(1-lactic acid)s. Polymer Degradation and Stability 91, 1665-1673. https://doi.org/10.1016/j.polymdegradstab.2005.12.009

Schliecker, G., Schmidt, C., Fuchs, S., Wombacher, R., Kissel, T., 2003. Hydrolytic degradation of poly(lactide-co-glycolide) films: Effect of oligomers on degradation rate and crystallinity. International Journal of Pharmaceutics 266, 39-49. https://doi.org/10.1016/S0378-5173(03)00379-X

Shi, D., Kang, Y., Zhang, G., Gao, C., Lu, W., Yang, C., Zou, H., Jiang, H., 2018. A comparative study on in vitro degradation behavior of PLLA-based copolymer monofilaments. Polymer Degradation and Stability 158, 148-156. https://doi.org/10.1016/j.polymdegradstab.2018.11.005

Siparsky, G.L., Voorhees, K.J., Miao, F., 1998. Hydrolysis of polylactic acid (PLA) and polycaprolactone (PCL) in aqueous acetonitrile solutions: Autocatalysis. Journal of Environmental Polymer Degradation $\quad 6, \quad 31-41$. https://doi.org/10.1023/A:1022826528673

Sun, Q., Rizvi, G.M., Bellehumeur, C.T., Gu, P., 2008. Effect of processing conditions on the bonding quality of FDM polymer filaments. Rapid Prototyping Journal 14, 72-80. 
https://doi.org/10.1108/13552540810862028

Tsuji, H., 2010. Hydrolytic Degradation, in: Poly(Lactic Acid). John Wiley \& Sons, Inc., Hoboken, NJ, USA, pp. 343-381. https://doi.org/10.1002/9780470649848.ch21

Tsuji, H., 2002. Autocatalytic hydrolysis of amorphous-made polylactides: Effects of L-lactide content, tacticity, and enantiomeric polymer blending. Polymer 43, 1789-1796. https://doi.org/10.1016/S0032-3861(01)00752-2

Tsuji, H., Mizuno, A., Ikada, Y., 2000. Properties and morphology of poly(L-lactide). III. Effects of initial crystallinity on long-term in vitro hydrolysis of high molecular weight poly(L-lactide) film in phosphate-buffered solution. Journal of Applied Polymer Science 77, 1452-1464. https://doi.org/10.1002/1097-4628(20000815)77:7<1452::AIDAPP7>3.0.CO;2-S

Tsuji, H., Muramatsu, H., 2001. Blends of aliphatic polyesters: V. Non-enzymatic and enzymatic hydrolysis of blends from hydrophobic poly(L-lactide) and hydrophilic poly(vinyl alcohol). Polymer Degradation and Stability 71, 403-413. https://doi.org/10.1016/S0141-3910(00)00192-0

Tyler, B., Gullotti, D., Mangraviti, A., Utsuki, T., Brem, H., 2016. Polylactic acid (PLA) controlled delivery carriers for biomedical applications. Advanced Drug Delivery Reviews 107, 163-175. https://doi.org/10.1016/j.addr.2016.06.018

Vieira, A.C., Vieira, J.C., Ferra, J.M., Magalhães, F.D., Guedes, R.M., Marques, A.T., 2011. Mechanical study of PLA-PCL fibers during in vitro degradation. Journal of the Mechanical Behavior of Biomedical Materials 4, 451-460. https://doi.org/10.1016/j.jmbbm.2010.12.006 
Wang, Y., Han, X., Pan, J., Sinka, C., 2010. An entropy spring model for the Young's modulus change of biodegradable polymers during biodegradation. Journal of the Mechanical Behavior of Biomedical Materials 3, 14-21. https://doi.org/10.1016/j.jmbbm.2009.02.003

Weir, N.A., Buchanan, F.J., Orr, J.F., Dickson, G.R., 2004. Degradation of poly-L-lactide. Part 1: in vitro and in vivo physiological temperature degradation. Proceedings of the Institution of Mechanical Engineers, Part H: Journal of Engineering in Medicine 218, 307-319. https://doi.org/10.1243/0954411041932782

Zhai, Y., Lados, D.A., LaGoy, J.L., 2014. Additive Manufacturing: Making Imagination the Major Limitation. JOM 66, 808-816. https://doi.org/10.1007/s11837-014-0886-2

Zhang, T., Jin, G., Han, X., Gao, Y., Zeng, Q., Hou, B., Zhang, D., 2019. Multiscale modelling for the heterogeneous strength of biodegradable polyesters. Journal of the Mechanical Behavior of $\quad$ Biomedical $\quad$ Materials $\quad 90, \quad 337-349$. https://doi.org/10.1016/j.jmbbm.2018.10.018 